\title{
Public Subsidy Of Health Care And Health Outcomes In OECD Countries
}

\author{
Adora Holstein, (E-mail: Holstein@rmu.edu), Robert Morris University
}

\begin{abstract}
This study determines if differences in per capita health care cost and health outcomes among $O E C D$ countries can be explained by the extent to which national health expenditures is publicly financed. The study controls, whenever multicollinearity issues can be avoided, for indicators of the quality of the health care system, health inputs and health risk factors. Using multiple regression analysis, the study finds that the quality of the health care system, not the extent of public subsidy, is the more statistically significant determinant of the cross-country variance in health outcomes.
\end{abstract}

\section{INTRODUCTION}

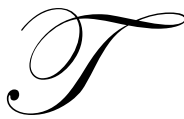

he political debate about whether the U.S. should move towards universal coverage is reemerging as a key issue in the upcoming presidential elections. Of the 30 members of the Organization for Economic Cooperation and Development (OECD) only the U.S., Turkey and Mexico do not have publicly funded health systems that cover all, if not the majority, of its residents. For all 30 countries, $94 \%$ of the population, on average, are covered by public health insurance (OECD Health Data 2006). Among the 27 countries that have universal coverage, funding of health care services are either from general tax revenues or from some kind of a separate social security fund. Medical services are, in rare cases (e.g. Great Britain and Spain), administered and provided by the government. In many cases, health care providers are private entities reimbursed by a single public payer (e.g. Canada, Denmark, Norway, Italy and Sweden) or by multi-payer sickness funds that pay annually negotiated, uniform rates for physicians and hospitals (e.g. France and Germany). Many countries also have private health insurance companies that sell coverage to those who can afford it and want to supplement the basic public insurance coverage.

The average composition of health care financing in OECD countries as of 2004 is public financing (73\%), out-of-pocket payments for copays, deductibles or for services not covered by public insurance (19\%), private health insurance and other private financing (8\%). In the U.S., the corresponding percentages are $45 \%$, $15 \%$, and $40 \%$ (OECD Health Data 2006). However, the public share of total health expenditure in the U.S. has grown faster than the average for all OECD countries since the 1980s. This faster growth is due to increasing support for universal coverage at the state level where several legislations have been passed to relax eligibility rules for Medicaid to cover adults with incomes up to $130 \%$ of the poverty threshold, and to expand coverage to children through the Children's Health Insurance Program (CHIP). More recently, Massachusetts passed a legislation making health insurance mandatory like car insurance, and providing low-cost health insurance from tax revenues to the not-so-poor but uninsured. At the Federal level, prescription drug coverage for the low-income elderly was added to the Medicare program in 2006.

\section{REVIEW OF RELATED STUDIES}

One component of the health care financing debate in the U.S. centers on what medical services would be cost-effectively paid for by public funds. Many would agree that public funds should pay for health care services of the poor because health care is a public good like education and would be underprovided by the private sector. Positive externalities that have been cited range from the more obvious fact that the spread of communicable diseases would be curbed if free immunization were available to all, to the increase in productivity arising from a 
healthy work force and global competitiveness arising from reduced absenteeism (Blanchette and Tolley, 1997). Musgrove (1999) advocated public financing of health services for which demand is inadequate (either because it involves rare diseases or there are substantial externalities involved), cost-effective interventions for the poor, health care services that are catastrophically costly even for the nonpoor, and when contributory insurance will not work. In a discussion paper released by The Hamilton Project, Jeanne Lambrew (2007) proposed universal health care coverage that is limited to preventive services and wellness promotion, with no required cost-sharing to increase utilization. The goal is to contain health care cost over the long-term by (a) promoting healthy lifestyles and (b) early detection and treatment of five chronic diseases (stroke, cancer, diabetes, cardiovascular and chronic obstructive pulmonary diseases) which account for two-thirds of all deaths in the U.S. Lambrew envisions that no new taxes need to be raised as funds can be carved out of existing public health care programs.

Supporters of universal health coverage argue that a single payer will be able to negotiate lower prices with health care providers, and administrative costs will be reduced. The high administrative costs of tracking eligibility, covered services, and reimbursement rates of multiple public and private health insurance organizations account for about 5\% of national health expenditure in the U.S., at least twice the share in countries with a single payer system. $\mathrm{Lu}$ and Hsiao (2003) found empirical evidence that Taiwan's adoption of universal health coverage has resulted in the reduction of the country's health care costs after controlling for demographic and economic changes over time. Other proponents of universal health coverage argue that countries where most, if not all, people have health insurance have longer life expectancies and lower infant mortality rates. Hogberg (2006) found this argument to be flawed because life expectancy and infant mortality do not depend on access to the health care system only, but also on genetics, diet, lifestyle risks, income, literacy, as well as incidence of accidents. One may add the effects of the incidence of crime and other environmental risks. Empirical studies using international data that support the multiplicity of health determinants include Ricci and Zachariadis (2006) and Furukawa (2005).

Holstein and Foreman (2007) provides a detailed review of empirical studies using data within the U.S. only. Using data for the 50 states of the U.S. from 1999-2002, they found that after controlling for socioeconomic factors, lifestyle and environmental risks, the interstate variances in both life expectancy and infant mortality rates were significantly associated with the generosity (measured by average spending per beneficiary) of the Medicaid health insurance program for the poor and the disabled. In an earlier study using international data, Holstein (2004) found that fairness of health care financing was a significant determinant of longer healthy life expectancy and lower infant mortality. She also found that the responsiveness of the health system was significantly associated with longer healthy life expectancy. Although that study controlled for literacy and health risks, however, it did not control for the role of the extent to which health expenditures are publicly funded. Thus, this study addresses this deficiency while controlling for the quality of the health care system, health inputs, and health risk factors.

\section{DATA AND METHODOLOGY}

In 2002, the OECD published a Health Systems Report based on a time-series database it developed for its 30 member countries (OECD Health Data 2002). Measures of performance or quality of health systems in 191 countries were developed by the World Health Organization (WHO) in 1999. A composite index of overall efficiency was derived from the weighted average of indices gauging the health system's responsiveness, the average healthy (or disability-free) life expectancy, and fairness in the distribution of financial burden (Arnesen and Nord, 1999; Wagstaff, et al, 1999). The U.S. ranked $37^{\text {th }}$, in a list in which France, Italy, and three small countries (San Marino, Andorra and Malta) were the top five. The index of responsiveness, in particular, was based on an international survey asking respondents to rate the promptness of intervention, choice of provider, and respect for patient's privacy, among others. The U.S. ranked first in responsiveness, followed by Switzerland, Luxembourg, Denmark and Germany. As to healthy life expectancy, the estimated 70.1 years of healthy life expectancy of an American male puts the U.S. in the $24^{\text {th }}$ place, in a list topped by Japan, Australia, France, Sweden and Spain. Fairness of the health system was gauged based on the extent to which other members of society through taxfinanced public subsidies share the health care cost of the elderly, the poor and the disabled. Here, the U.S. ranked $54-55$ (a tie with Fiji) in a list headed by Columbia, Luxembourg, Belgium, Denmark and Germany (World Health Report 2000). 
Table 1 compares the U.S. with a peer group of 22 other OECD countries with per capita heath care costs (PCHC) above \$1,000 adjusted for purchasing power parity (PPP). The U.S. ranks first in terms of per capita health care cost and the responsiveness of the health care system. However, it lags behind its peer group in terms of health outcomes (combined male and female average life expectancy, healthy male life expectancy, and infant mortality rate, share of public financing, fairness of health care financing, availability of physicians, and the prevalence of smoking).

Table 1

Descriptive Health-related Statistics for OECD Countries, 1999

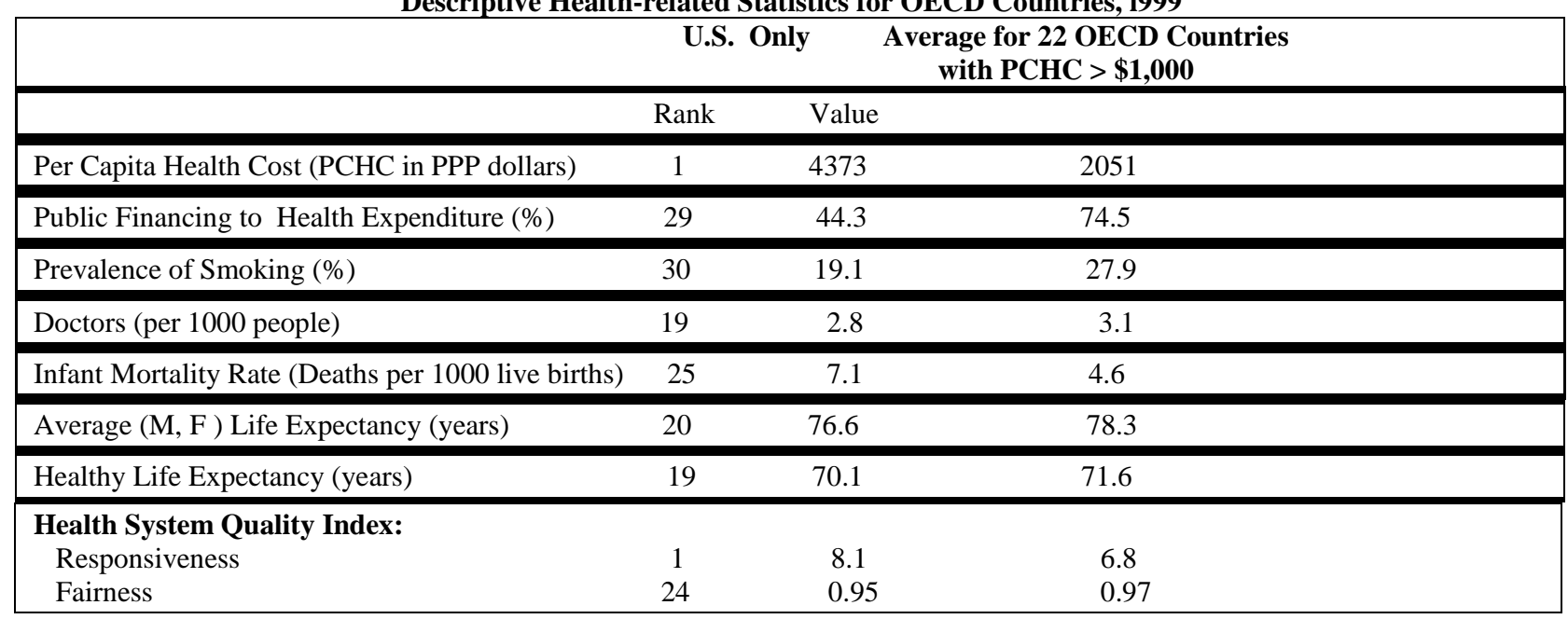

Sources: OECD Health Data 2002: A Comparative Analysis of 30 Countries: 2002 ed.

World Health Report 2000 (Geneva: World Health Organization, 2000).

The WHO's indices of the health care system's responsiveness and fairness of financing for 1999 are matched with same year OECD data on per capita health expenditure, healthy life expectancy, average of male and female life expectancies, public share of health expenditure, the availability of physicians, and a health risk factor prevalence of smoking. Other possible control variables (health care inputs, share of medical durables to total expenditures, educational attainment, out-of-pocket payments) were excluded because their inclusion in a multiple regression analysis would prevent me from isolating the separate effect of the public share of health expenditure (i.e. their correlation coefficients with this variable of interest exceeded 0.10 ). The regression equations estimated are:

\begin{tabular}{|c|c|c|c|}
\hline PCHC & $=$ & $b_{10}+b_{11}$ PUBHX $+b_{12}$ RESP & $+b_{13}$ RISK \\
\hline HLXP & $=$ & $-b_{21}$ PUBHX $+b_{22}$ RESP & $+b_{23}$ RISK \\
\hline $\mathrm{XP}$ & $=$ & $\mathrm{b}_{31}$ PUBHX $+\mathrm{b}_{32}$ RESP & RISK \\
\hline MI & & $\mathrm{b}_{41}$ PUBHX $+\mathrm{b}_{42}$ RESP & DOCS \\
\hline M & & ${ }_{1}$ PUBHX - & DOCS \\
\hline
\end{tabular}

where PCHX is the per capita health care expenditure, PUBHX is the public share of health care expenditure, HLXP is healthy (disability-free) male life expectancy, LXP is the average of male and female life expectancies not adjusted for disabilities, IMR is infant mortality rate, RESP is the responsiveness index of the health care system, RISK is the prevalence of smoking (a health risk proxy), FAIR is the fairness index of the health care system, and DOCS is the availability of physicians.

A semi-logarithmic functional form is used in Eq.1 to ensure non-negative predicted values for PCHC. To determine the role of the public share of health expenditure in explaining the cross-country variance in infant mortality rates (IMR), countries with very high IMR like Mexico and Turkey are excluded. In addition, the U.S. is excluded because the way live births are defined in this country makes the calculated IMR significantly different 
from other OECD countries (Hogberg 2006). With a sample size (n) of 27 countries, it was possible to include the availability of physicians as a control variable, and also to alternately use health system responsiveness and fairness of health care financing as indicators of the quality of the health care system.

Table 2 provides a correlation matrix for the variables used in the analysis. The null hypotheses to be tested can be summarized as:

$b_{11}=b_{12}=b_{13}=b_{21}=b_{22}=b_{23}=b_{31}=b_{32}=b_{33}=b_{41}=b_{42}=b_{43}=b_{51}=b_{52}=b_{53}=0$

Table 2

Correlation Matrix

\begin{tabular}{|c|c|c|c|c|c|}
\hline & PUBHX & PCHX & HLXP & LXP & IMR \\
\hline Responsiveness (n=30) & -0.05 & 0.94 & 0.68 & 0.77 & -0.72 \\
\hline Fairness (n=27) & 0.27 & 0.74 & 0.70 & 0.78 & -0.42 \\
\hline Prevalence of Smoking (n=30) & -0.09 & -0.30 & -0.26 & -0.07 & 0.13 \\
\hline Availability of Physicians (n=27) & 0.17 & 0.21 & 0.24 & 0.17 & -0.44 \\
\hline
\end{tabular}

Table 3

Determinants of Health Care Cost

\begin{tabular}{|c|c|c|}
\hline Explanatory/Policy Variables & Std. Coefficients & t-statistics \\
\hline Public Share of Health Expenditure (\%) & 0.01 & 1.63 \\
\hline Responsivess Index & $0.82 * * *$ & 13.02 \\
\hline Prevalence of Smoking & -0.00 & -0.69 \\
\hline Constant & $1.75 * * *$ & \\
\hline 0.88 & & \\
\hline Adj. $R^{2}$ & & \\
\hline 65.67 & & \\
\hline
\end{tabular}

Table 4

Determinants of Health Outcomes

\begin{tabular}{|llccc||}
\hline \hline Explanatory/Policy Variables & HLXP & LXP & IMR & IMR \\
Public Share of Health Exp. (\%) & 0.04 & 0.01 & -0.02 & -0.01 \\
Responsivess Index & $3.05^{* * *}$ & $2.80^{* * *}$ & $-1.91^{* * *}$ & $-59.95^{* * *}$ \\
Fairness Index & & & \\
Prevalence of Smoking & -0.01 & -0.06 & -0.06 & -0.08 \\
Availability of Physicians & & & $19.05^{* * *}$ & $64.19 * * *$ \\
Constant & $47.54 * * *$ & $59.91 * * *$ & 0.53 & 0.66 \\
R $^{2}$ & 0.50 & 0.55 & 0.47 & 0.61 \\
Adj. $\mathbf{R}^{2}$ & 0.44 & 0.50 & 8.64 & 14.72 \\
F & 8.63 & 10.78 & & \\
\hline
\end{tabular}

\section{ANALYSIS OF FINDINGS}

The regression coefficients of equation 1 are summarized in Table 3 while the regression coefficients of equations 2 to 5 are summarized in Table 4. There exists a positive but weak statistical association between the public share of health expenditure and per capita health care cost. This would imply that increased public financing of health care cost does not necessarily lead to lower average health care cost. What seems to be a more important determinant is the responsiveness of the health care system. The more responsive the country's health care system is, the higher is its per capita health care cost. 
The responsiveness of the health care system is also found to be a statistically significant positive determinant of both measures of life expectancy (healthy life expectancy and average life expectancy). Likewise, the study finds that the more responsive the health care system is and the more that health care financing is shifted to the nonpoor and healthy, the lower the infant mortality rate (see Table 4). The public share of health expenditure, the proxies for health risk (prevalence of smoking) and health care input (availability of physicians) are not significant determinants of the chosen measures of health outcomes.

\section{CONCLUSION AND POLICY IMPLICATIONS}

Limited data for OECD member countries suggest that increased public financing of health care expenditures, by itself, may not lead to cost containment or better health outcomes. While increased public financing of health care can be supported on grounds of economic efficiency and equity, it is more important that policy makers focus on improving the responsiveness of the health care system and making sure that the burden of tax revenues is shifted from the poor and the sick to the nonpoor and healthy.

\section{SUGGESTIONS FOR FUTURE RESEARCH}

The sample of 30 OECD member countries analysed in this study can be increased to the 191 member countries of the World Health Organization. It is important, in my opinion, that the sample be split between high and low national income countries, or to control for national income, and to address multicollinearity problems when choosing explanatory variables.

\section{REFERENCES}

1. Blanchette, C. and E. Tolley, Public and Private Sector Involvement in Health Care Systems: Comparison of OECD Countries. Economics Division, Govt. of Canada. February 2001.

2. Congressional Budget Office, Rising Health Care Costs: Causes, Implications and Strategies, CBO, Washington D.C., April 1991.

3. Hogberg, David, Don't Fall Prey to Propaganda: Life Expectancy and Infant Mortality are Unreliable Measures for Comparing the U.S. Health Care System to Others. www.nationalcenter.org/NPA547ComparativeHealth.html, July 2006.

4. Holstein, Adora, Health Outcomes and the Cost-Quality Trade-off in Health Care: Empirical Study of OECD Countries. International Business Economics Research Journal, Vol3, No. 7, pp.57-62, 2004.

5. Holstein, Adora and Stephen Foreman, Interstate Variances in Health Outcomes and Medicaid Program Generosity, March 2007 (under review - Pennsylvania Economic Journal).

6. Lambrew, Jeanne, A Wellness Trust to Prioritize Disease Prevention, The Hamilton Project Policy Brief No. 2007-04, pp. 8-10, The Brookings Institution, April 2007.

7. Lu, Rachel and W. C. Hsiao, Does Universal Health Insurance Make Health Care Unaffordable? Lessons from Taiwan, Health Affairs, Vol.22, No.3, pp. 77-88, 2003.

8. Musgrove, Philip, Public Spending on Health Care: How Are Different Criteria Related? Health Policy, Vol. 4, pp. 207-223, 1999.

9. Organization for Economic Cooperation and Development, OECD Health Data 2002: A Comparative Analysis of 30 Countries, 2002 ed.

10. World Health Organization, The World Health Report 2000 - Health Systems: Improving Performance, WHO, Geneva, 2000. 


\section{NOTES}

